\title{
Aus dem Vorwort
}

\section{zum \\ „Preußischen Nachbarrecht“}

Die vorliegende Abhandlung enthält die gesamten, auf das Nachbarrecht bezüglichen Vorschriften des Reichs- und Landesrechts mit Einschluß des Rechts der Grunddienstbarkeiten, jedoch unter Ausscheidung des Wasserrechts. Es wurde darauf Bedacht genommen, den Zusammenhang des neuen Rechts mit den alten Rechtsquellen einschließlich der Partikularrechte herzustellen. Die öffentlich-rechtlichen Normen sind insoweit einbezogen, als dies mit Rücksicht auf den Zweck einer zusammenfassenden Darstellung des Nachbarrechts geboten schien.

Unbeschadet des Strebens nach wissenschaftlicher Durchdringung des Stoffes ist darauf Bedacht genommen, durch klare und gemeinverständliche Sprache auch dem Laien die Handhabung des Buches zu ermöglichen. Das eingehende Sachregister und das reichhaltige Wortverzeichnis wird dies wesentlich erleichtern

Würzburg und Berlin, im September 1926

Christian Meisner. Heinrich Stern 